aortic dissection with severe aortic regurgitation in a 30-yearold man who had initial TOF repair at the age of 21 years. His ascending aorta was $71 \mathrm{~mm}$ in diameter. The patient survived after undergoing a Bentall operation with mechanical prosthesis. The second patient ${ }^{5}$ was a 36 -year-old man who had TOF repair at the age of 6 years and developed dissection of an ascending aortic aneurysm that was $93 \times 83 \mathrm{~mm}$. The outcome of this patient was not reported. Although dissection is rare in children, those with aneurysms must be monitored closely. Why should aortic aneurysms behave differently when the wall stresses are subject to the same laws of physics?

\section{CONCLUSIONS}

Dissection of the aortic root can occur in an adolescent after TOF repair. Aortic dissection must be included in the differential diagnosis of any patient after TOF repair presenting with sudden-onset chest pain, especially those with a dilated ascending aorta.

\section{References}

1. Zalzstein E, Hamilton R, Zucker N, Diamant S, Webb G. Aortic dissection in children and young adults: diagnosis, patients at risk, and outcomes. Cardiol Young. 2003;13:341-4.

2. Tan JL, Gatzoulis MA, Ho SY. Aortic root disease in tetralogy of Fallot. Curr Opin Cardiol. 2006;21:569-72.

3. Niwa K, Siu SC, Webb GD, Gatzoulis MA. Progressive aortic root dilatation in adults late after repair of tetralogy of Fallot. Circulation. 2002;106: 1374-8.

4. Kim WH, Seo JW, Kim SJ, et al. Aortic dissection late after repair of tetralogy of Fallot. Int J Cardiol. 2005;101:515-6.

5. Rathi VK, Doyle M, Williams RB, et al. Massive aortic aneurysm and dissection in repaired tetralogy of Fallot: diagnosis by cardiovascular magnetic resonance imaging. Int J Cardiol. 2005;101:169-70.

\title{
Simple preoperative management for cold agglutinins before cardiac surgery
}

Shinji Kanemitsu, MD, Koji Onoda, MD, Kiyohito Yamamoto, MD, and Hideto Shimpo, MD, Tsu City, Japan

Cold agglutinins (CAs) are of particular relevance in cardiac surgery because of the use of hypothermic cardiopulmonary bypass. CAs activate at varying levels of hypothermia and can cause catastrophic hemagglutination, microvascular thrombosis, or hemolysis. The detection of CAs before operation may change the management of cardiopulmonary bypass and myocardial protection. We describe here a case of aortic valve replacement in which CAs with high titer and high thermal amplitude were detected preoperatively.

\section{CLINICAL SUMMARY}

A 72-year-old woman was seen with severe aortic valve stenosis. The patient had no symptoms related to CAs, although preoperative testing demonstrated an elevated CA

\footnotetext{
From the Department of Thoracic and Cardiovascular Surgery, Mie University Graduate School of Medicine, Tsu City, Japan.

Disclosures: None.

Received for publication May 8, 2010; revisions received June 10, 2010; accepted for publication June 21, 2010; available ahead of print July 15, 2010.

Address for reprints: Shinji Kanemitsu, 2-174, Edobashi, Tsu, Mie 514-8507, Japan (E-mail: skanemitsu70@clin.medic.mie-u.ac.jp).

J Thorac Cardiovasc Surg 2010;140:e73-4

$0022-5223 / \$ 36.00$

Copyright (C) 2010 by The American Association for Thoracic Surgery

doi:10.1016/j.jtcvs.2010.06.030
}

titer (1:512) at $4^{\circ} \mathrm{C}$, and the thermal amplitude for agglutination was determined as $20^{\circ} \mathrm{C}$. We administered a high dose (15 g) of immune globulin (IgG) just before surgery, after which the CA titer decreased to 1:64. In light of this value, we decided to perform the operation with normothermic cardiopulmonary bypass and continuous retrograde and intermittent antegrade tepid blood cardioplegia. Precautions were taken intraoperatively to avoid exposure to agents within the active temperature range for CAs. Anesthetic agents and fluids were warmed. The aortic crossclamp was applied, and induction cardioplegia was administered retrogradely into the coronary sinus at $28^{\circ} \mathrm{C}$. The delivery rate of continuous retrograde cardioplegic solution was $200 \mathrm{~mL} / \mathrm{min}$. The pressure in the coronary sinus was maintained at approximately $40 \mathrm{~mm} \mathrm{Hg}$. Effective absorption was used to obtain an optimized operative field without interruption of continuous retrograde cardioplegia. The aortic valve was successfully replaced. The patient was weaned successfully from cardiopulmonary bypass and did not require support with inotropes. A myocardial temperature probe was placed into the anterior wall for continuous monitoring. The lowest rectal and myocardium temperatures were $32.5^{\circ} \mathrm{C}$ and $27.2^{\circ} \mathrm{C}$, respectively. No signs of hemolytic or vaso-occlusive complications were seen. No electrocardiographic or enzymatic evidence of myocardial injury was apparent. 


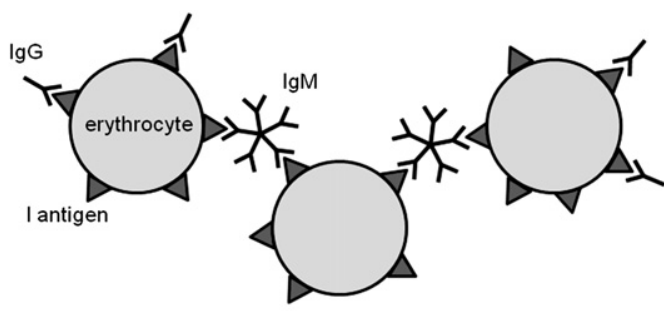

A

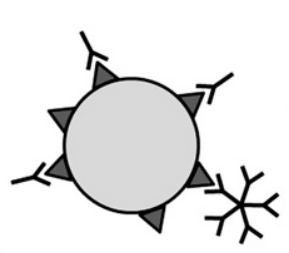

B
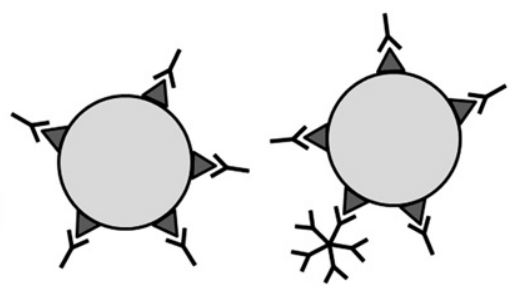

FIGURE 1. A, Mechanism of blood agglutination at low temperatures from interactions between cold agglutinins (IgM) and I antigens on surface of erythrocytes. B, High-dose immune globulin $(\operatorname{Ig} G)$ prevents interaction between $\operatorname{IgM}$ and erythrocytes by the coating of I antigens on erythrocytes.

\section{DISCUSSION}

The presence of CAs, predominantly IgM antibodies mediated against I antigens on erythrocytes (Figure 1, A), is relatively common in an infective process (mycoplasmal pneumonia) or a lymphoproliferative disorder. Although most patients with CAs remain free of symptoms, a high titer and high thermal amplitude of CAs can lead to hemagglutination, followed by complement fixation and subsequent hemolysis on rewarming. The reported incidence of CAs among screened cardiac surgical patients is approximately $0.8 \%$ to $4 \%{ }^{1}$

The perioperative management for cardiac surgical patients with CAs remains controversial. In a review of 50 cases of patients with CAs between 1969 and 1995, steroids, azathioprine, and cyclophosphamide were found to be of no benefit. ${ }^{1}$ Plasma exchange is the ideal method for removing large quantities of IgM, because approximately $95 \%$ of IgM in the body is intravascular and a single $5-\mathrm{L}$ plasma exchange can remove as much as $80 \% .^{2}$ Nevertheless, there have been few reports either of successful plasma exchange $^{3}$ or of failure ${ }^{4}$ with this technique. Plasma exchange requires high volumes of blood products and is prohibitively expensive, and although it can achieve an
8- to 10-fold reduction in CA titers, there are risks of large volume shifts, infection, and altered hemostasis. In contrast, $\mathrm{IgG}$ therapy is both easier to perform and less expensive than plasma exchange. In our case, high-dose immune globulin administration just before cardiac surgery caused an 8-fold reduction in the titer of CAs. We speculate that agglutination at low temperatures caused by the interactions between $\operatorname{IgM}$ and erythrocytes may have been prevented by the coating of antigens onto erythrocytes by the high-dose immunoglobulin (Figure 1, B). CA titer degradation is necessary when performing operations with deep hypothermic circulatory arrest, especially aortic surgeries.

Thermal amplitude should be quantified preoperatively, thus giving the surgeon a temperature range in which to work. For myocardial protection, cardioplegia at higher temperatures is the most common strategy. Warm or tepid blood cardioplegia, coronary arterial blood washout with normothermic crystalloid cardioplegia, and normothermic, noncardioplegic, and intermittent fibrillatory arrest have been successfully performed. ${ }^{1}$ Systemic normothermia or mild hypothermia, depending on thermal amplitude of the antibody, is also an option. This technique involves maintaining tissues above the activation threshold of agglutination by warming the operating room and all fluids. Strict core temperature monitoring should be used, together with the simple addition of myocardial temperature monitoring to prevent activation of CAs. Our case demonstrates that tepid blood cardioplegia is an appropriate and safe technique. The blood should be infused continuously to maintain tissue perfusion and prevent microvascular clotting.

In summary, preoperative high-dose immune globulin administration just before surgery in a patient with CAs is an easy and attractive therapy.

\section{References}

1. Agarwal SK, Ghosh PK, Gupta D. Cardiac surgery and cold-reactive proteins. Ann Thorac Surg. 1995;60:1143-50.

2. Powles R, Smith C, Kohn J, Hamilton Fairley G. Method of removing abnormal protein rapidly from patients with malignant paraproteinaemias. Br Med J. 1971;3:664-7.

3. Andrzejewski C Jr, Gault E, Briggs M, Silberstein L. Benefit of a 37 degree C extracorporeal circuit in plasma exchange therapy for selected cases with cold agglutinin disease. J Clin Apher. 1988;4:13-7.

4. Rodenhuis S, Maas A, Hazenberg CA, Das PC, Nieweg HO. Inefficacy of plasma exchange in cold agglutinin hemolytic anemia-a case study. Vox Sang. 1985;49: 20-5. 